\title{
THE CONCENTRATION OF UREA IN THE BLOOD OF NORMAL INDIVIDUALS ${ }^{1}$
}

\author{
By EATON M. MACKAY AND LOIS LOCKARD MACKAY \\ (Department of Medicine of Stanfurd University Medical School, San Francisco, California)
}

(Received for publication February 8, 1927)

The concentration of urea may be determined more easily and with greater accuracy than that of any other non-protein nitrogenous constituent of the blood. We have shown elsewhere (1) that the blood urea concentration ordinarily increases little above its usual level until the amount of functioning renal tissue has been reduced by more than half. Since a decreased renal function is not of immediate importance to the patient until such a degree (50 per cent) of reduction in the renal substance has taken place, the concentration of urea in the blood becomes an excellent clinical index of renal failure. An increase in the blood urea concentration above the normal range is then of great importance. The small number of subjects in the various series which have been published and the disparity of the results obtained have led us to collect further data relating to the blood urea concentration of normal individuals.

In figure 1 the series of normal blood ureas which have been reported in the literature are briefly summarized. Only those groups of observations which were obtained, with two exceptions, from ten or more normal subjects and in which a reasonably reliable blood urea method was used have been included. The earlier and less reliable figures have been summarized by Schwartz and McGill (7).

An examination of figure 1 shows a large degree of variation between the "normal range" and the mean values of the different groups of observations. Moreover the number of observations in any single series is too small to draw any conclusions of a general nature.

${ }^{1}$ This work was aided by the Wellington Gregg Fund for the Investigation of Bright's Disease. 
Pep cent of observations
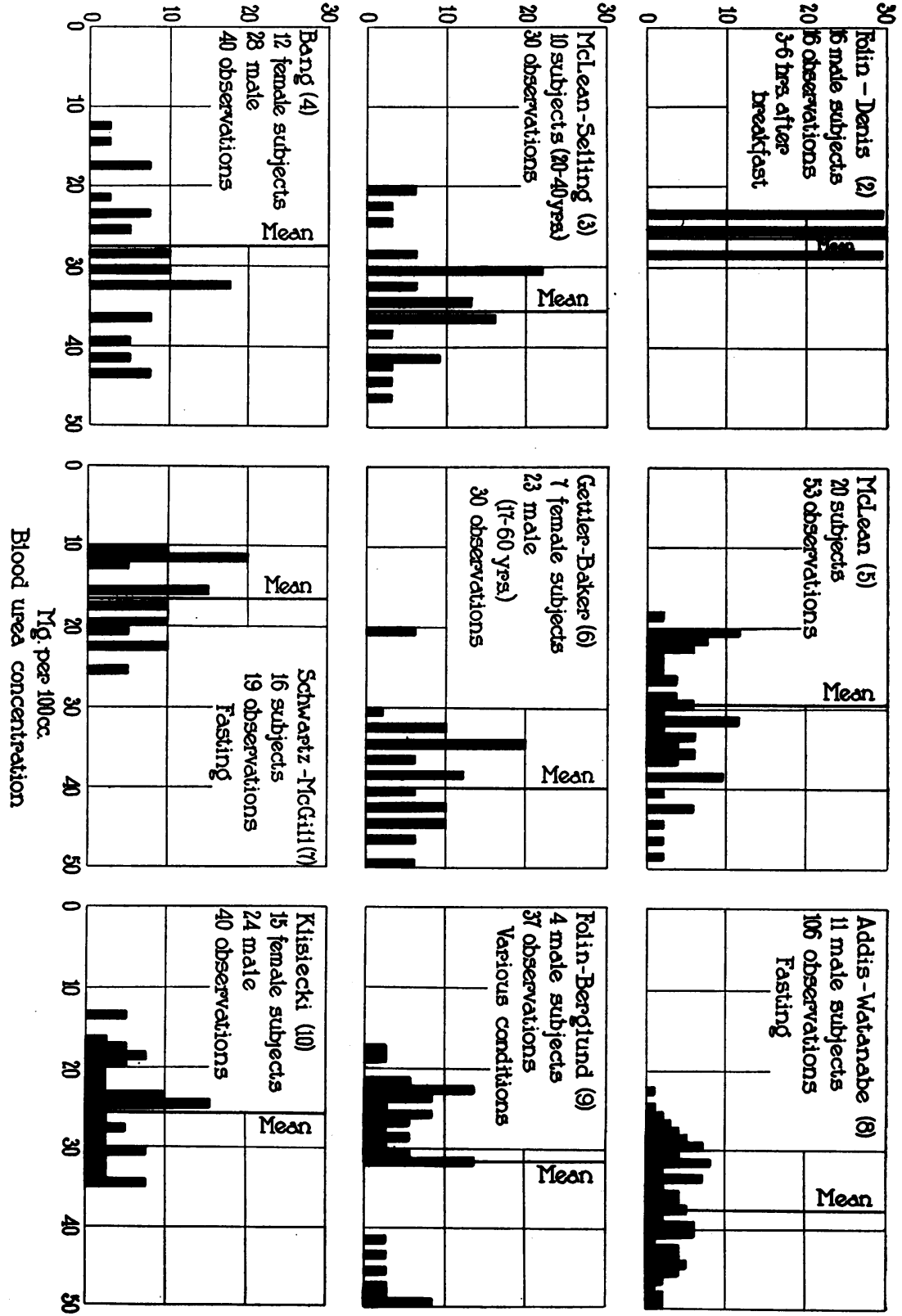

FIG. 1 


\section{METHODS}

All of the observations which are reported here were obtained from individuals who were apparently normal and in good health. Most of them were medical students although some nurses, laboratory technicians and physicians served as subjects. In no instance did the individual have an albuminuria or a suggestive history.

Venous blood, drawn with momentary stasis from one of the peripheral veins of the elbow was used for analyses. This contained a small amount of powdered potassium oxalate to prevent coagulation. Although, as a result of its higher water content, the plasma contains a slightly higher concentration of urea than whole blood the difference is so small as to be negligible for practical purposes. Furthermore the error ${ }^{2}$ such as it is, is greater between oxalated plasma and plasma obtained with hirudin or without an anticoagulant than the difference between the urea concentration of whole blood and its true plasma. Whole blood was therefore used for the analyses. Urea was determined on duplicate specimens according to the urease method described by Addis (11).

\section{VARIATION OF THE BLOOD UREA DURING THE DAY}

Before proceeding to collect observations it was first necessary to find the conditions which best suited the determination of a normal. To do this we have ascertained the effect of meals, daily activity and sleep on the blood urea concentration. The experiment was carried out on a group of six young adult males (medical students) whose daily activities were about the same. For several days before the experiment they had been weighing their food and preparing diet sheets and the special diet which they received was based on the average of these. Each individual received 1.1 gram of protein and 36 calories per kilogram of body weight per day. The special diet was given not only during the period of observation but for 5 days preceding it. Water was taken as desired. Each man in the group took his meals at the same time and slept about the same number of hours. The subjects were awakened in the morning to take the first blood specimens and the last of the day was taken on retiring. Other details regarding the time of specimens are given in figure 2.

${ }^{2}$ We have found that the crenation of the red cells and the decrease in cell volume which takes place on adding an anticoagulant, such as dry potassium oxalate, to blood results in the addition to the plasma of fluid from the cells which has a urea content higher than that of the plasma. 
During the two days and nights of observation the blood urea did not remain constant. The variations which are present in the members of the group are not the same in each case or always in the same

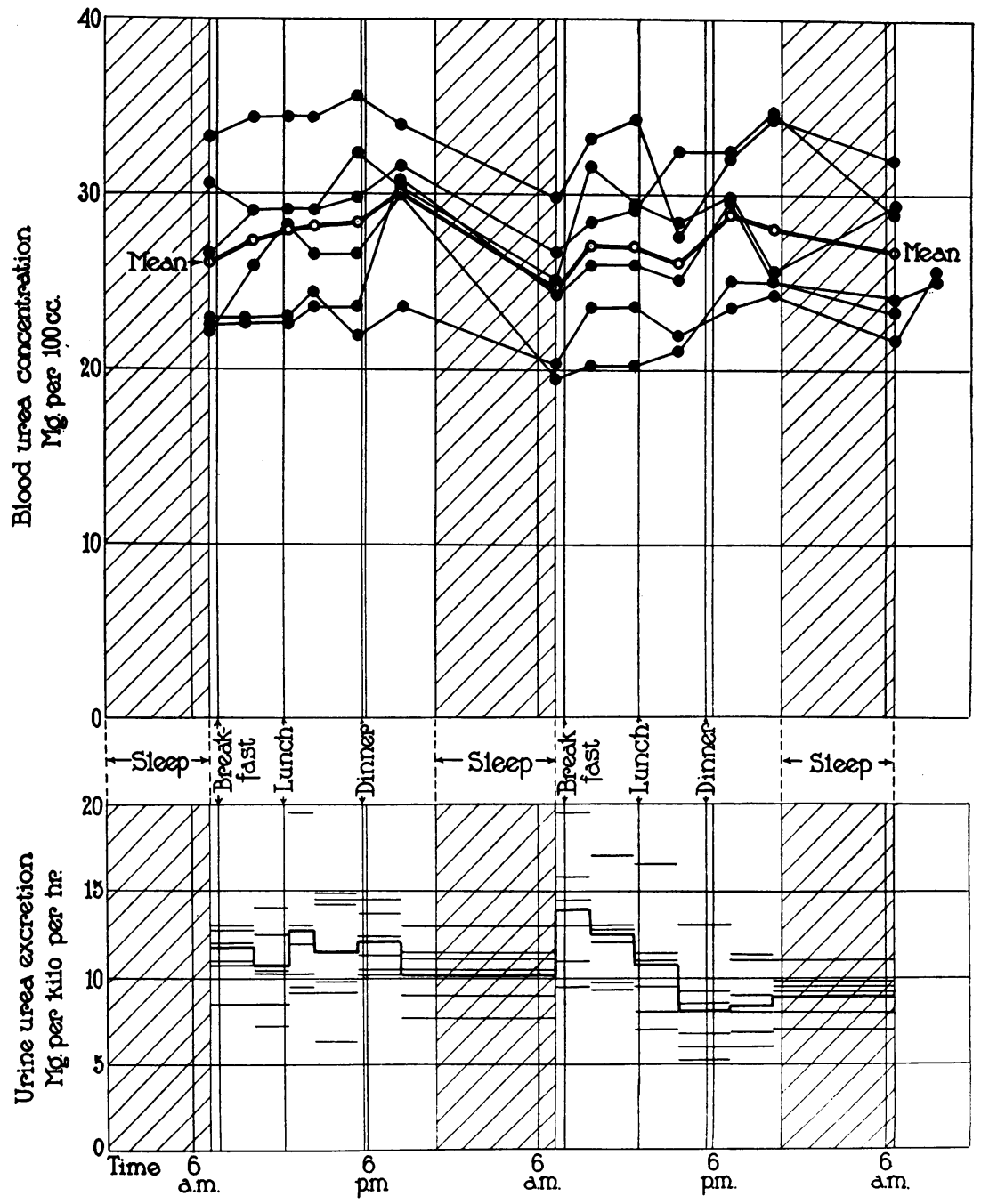

FIg. 2

direction. However, in the average curve an interesting variation is present which is repeated in a general way during each 24-hour period and which is supported by a large majority of the individual observa- 
tions. This is the undeniable tendency of the blood urea concentration to increase throughout the daytime or active hours and to fall again during the night or period of sleep. In another experiment somewhat similar to this one but unsuitable for inclusion here this variation was found to be even more evident.

The reason for the day rise and night fall in the blood urea is not plainly evident. The ingestion of food and hence of protein during the day may contribute to the daily rise. This seems probable because the most acute rise follows the evening meal (dinner) which contained the most protein. It is certain that changes in the degree of renal activity are at least not primarily responsible, for the urine urea excretion is much less during the night than during the day, a finding directly opposite to that which would be expected if variation in this factor caused the blood urea variation. A general examination of the various curves would seem to indicate that the variation is more dependent on changes in the general metabolic rate than any other factor. The blood urea decrease during the night would then be associated with a decrease in the general metabolic processes which is known to ensue and especially with a decrease in the activity of protein catabolism. It is noteworthy that the two most rapid increases in the blood urea concentration which were recorded covered periods during which the subjects engaged in several strenuous games of tennis.

Although the experiment just discussed gives little reason for selecting a particular time of day for drawing blood for urea estimations, a high protein diet without doubt increases the blood urea (8) above its usual level and in the case of an individual accustomed to a large protein intake it might seem wise to draw blood before breakfast. But we have found in experiments not included here that single high protein meals such as might conceivably be taken in ordinary life have only a minor effect on the blood urea concentration. If on the other hand an increased protein intake (e.g., 1.7 instead of 1.1 gram per kilogram of body weight such as was used in our experiment) is maintained from day to day a more important increase in the blood urea takes place. The same day and night variation which we described is still present but at a new and higher urea level. Since the increase is present in a comparable degree at all times little would be gained even with these individuals by taking specimens at any particular time of day. 
THE NORMAL BLOOD UREA CONCENTRATION

However interesting the normal daily variation in the blood urea concentration may be it is not, as has been pointed out, of such magnitude as to have much practical significance in regard to the time of day at which blood for a urea estimation is taken. In collecting ob-

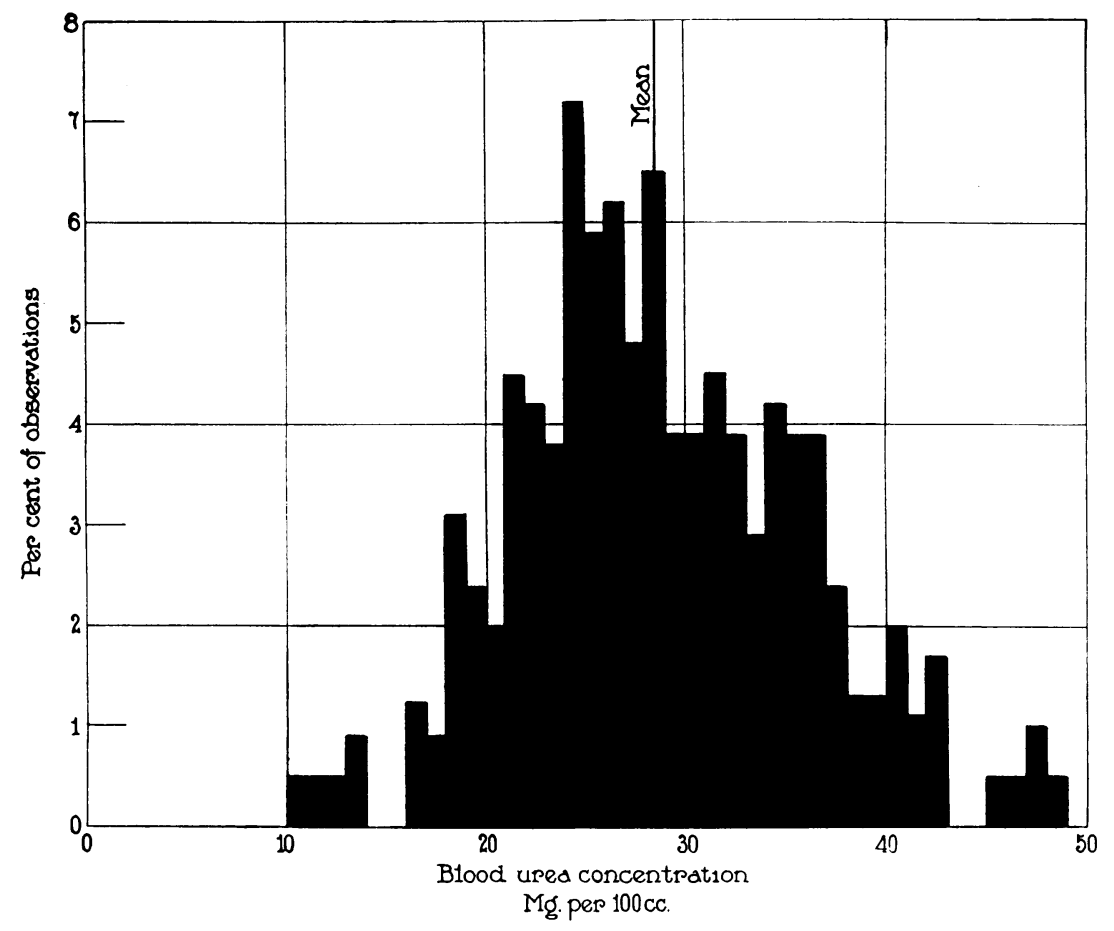

Fig. 3. Distribution of 278 (220 on Males and 58 on Females)

OBSERVATIONS

servations with which to establish a normal average it was therefore not deemed necessary to restrict the collection of blood specimens to any particular time. By chance it happens that most of them were obtained in the forenoon. A total of 278 observations were made, 58 on 47 female subjects and 220 on 114 different male subjects. The youngest subject was 18 years of age and the oldest 49 years. Other data pertaining to the age distribution is given in figure 4 . The dis- 
tribution of the observations composes figure 3. The statistical significance of the mean value of our group of observations forms table 1.
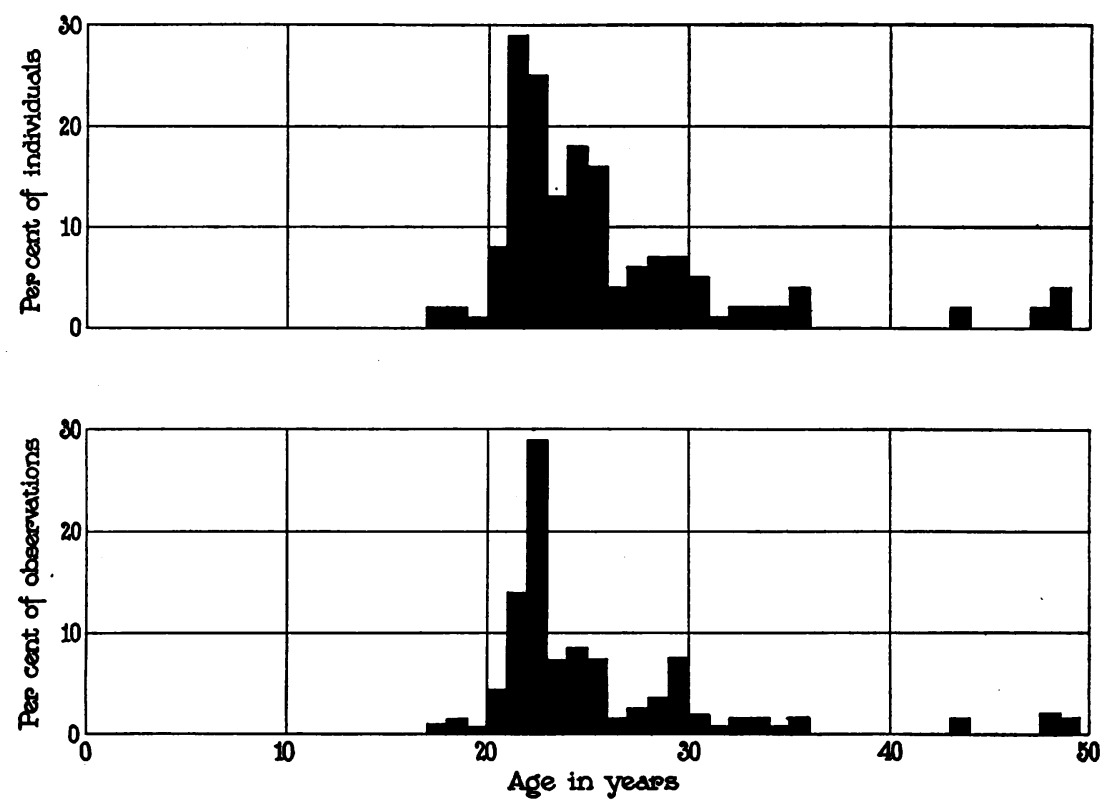

Fig. 4. Source of Observations Comprising Figure 3

TABLE 1

Blood urea concentration (milligrams per 100 cc. blood)

\begin{tabular}{|c|c|c|c|}
\hline & All observations & Males & Females \\
\hline Number of observations. . . . . . . . . . . . & $278 \dagger$ & $(58)^{*}$ & 58 \\
\hline High. .............. & 48.0 & 46.2 & 39.0 \\
\hline Low............. & 11.0 & 25.8 & 11.0 \\
\hline Mean Value............... & 29.3 & 33.0 & 24.4 \\
\hline Standard Deviation..... & 6.98 & 4.60 & 5.88 \\
\hline Probable Error of the Average........... & 0.28 & 0.40 & 0.52 \\
\hline Coefficient of Variability $\ldots \ldots \ldots \ldots \ldots \ldots$ & 4.01 & 8.70 & 8.85 \\
\hline
\end{tabular}

* See text.

$\dagger$ Two hundred and twenty observations on 114 males and 58 observations on 47 females.

This mean value, 29.3 milligrams of urea per $100 \mathrm{cc}$. of blood, probably represents the normal average pretty closely. It might, however, in 
the light of sex differences to be discussed shortly, have been a few milligrams lower if our observations on female subjects had been equal in number to those on males.

The lowest value obtained was 11.0 and the highest $48.0 \mathrm{mgm}$. of urea per $100 \mathrm{cc}$. of blood. Although there is a possibility, the chances are small, that any normal figures will fall outside of this range. It seems safe to conclude that 50 is the upper limit of normal and that any value over this figure should be considered pathological. The lower limit has not the same interest attached to it but since in certain types of renal disease the blood urea becomes lowered it is a point worthy of consideration. A blood urea lower than $10.0 \mathrm{mgm}$. per $100 \mathrm{cc}$. of blood may be considered of questionable normality.

RELATION OF THE BLOOD UREA CONCENTRATION TO SEX

As we proceeded to collect observations of the blood urea concentrations in normal individuals it became increasingly evident that female subjects tended to give lower values than males. After we found that this was true the same observation was made by Klisiecki (10) who found in a short series of subjects that the figures for males were markedly higher than for females. It seems worth while to offer confirming evidence on this point.

Fifty-eight observations on 47 female subjects were available. It was desirable that they be paired for comparison with a similar number of figures from a group of male subjects with the same age distribution. In order to avoid selection in choosing the latter all of the male values for a given age were averaged and the average repeated in the comparative male series the number of times that the age appeared in the female group. In figure 5 the distribution of the two groups, male and female, have been compared. There can be no question that in general the blood urea concentration tends to be higher in a male than in a female subject. The significance of the averages of the groups is given in table 1 . The average of the male group is 35 per cent higher than the average of the female group. Determined in the usual manner the probable difference between the averages is 0.66 while the observed difference is 8.60 .

It is generally supposed that the protein intake (per unit body weight) of males is higher than that of females. Then we know (12) 


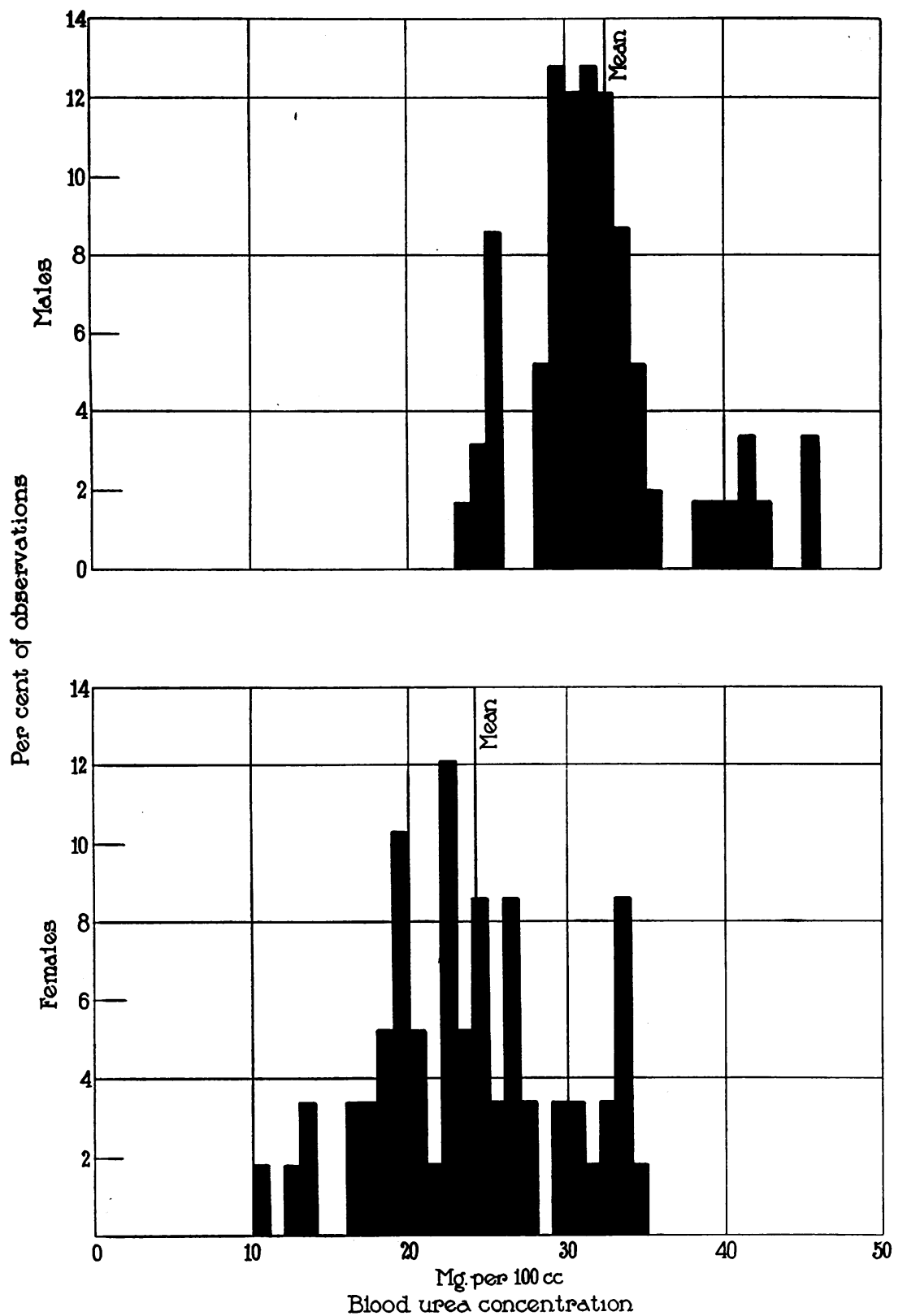

Fig. 5. Fifty-eight Observations from a Group of Male Subjects Compared with a Similar Number from a Comparable Group of Female Subjects 
that the basal metabolic rate and therefore, probably, the rate of protein catabolism, is slightly higher (per unit body surface) in male subjects than in females of the same age. These facts suggest a possible explanation of the sex difference in the blood urea which has just been noted although it may not be the correct one.

\section{RELATION OF THE BLOOD UREA TO AGE}

Our observations are inadequate both in age distribution and number to determine conclusively the relation, if any, of the blood urea concentration to age. There does however seem to be a tendency for the blood urea to increase with age. The definite presence of a similar

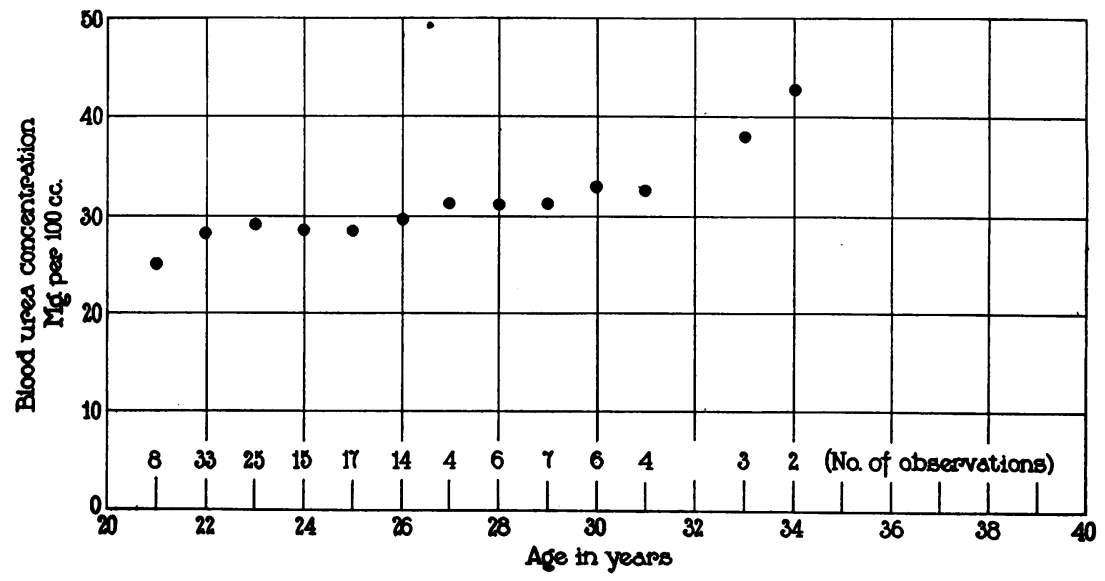

FIG. 6

increase in the blood ureas of a large group of albino rats in which most of the factors could be controlled has prompted us to point out the similar tendency in our observations on man.

In figure 6 have been plotted the average blood urea concentrations for groups of male subjects of various ages. The curve suggests an increase of blood urea concentration with increase in age.

\section{SUMMARY}

Although not of such magnitude as to be of practical significance the blood urea concentration of normal individuals undergoes a meas- urable fluctuation during the day and night. In general the blood 
urea concentration has a tendency to fall during the night only to rise again during the following day.

The blood urea concentrations of a group of normal individuals were determined. A total of 278 observations were made, 58 on 47 female subjects and 220 on 114 male subjects. A high value of 48.0 , a low of 11.0 and a mean of $29.3 \mathrm{mgm}$. of urea per $100 \mathrm{cc}$. of blood were found for the group. The limits of the normal blood urea concentration have tentatively been placed at 10.0 to $50.0 \mathrm{mgm}$. per $100 \mathrm{cc}$. of blood.

The blood urea concentrations of male subjects have been found to be higher than those of comparable female subjects. In the male group a high value of 46.2 , a low of 25.8 and a mean of $33.0 \mathrm{mgm}$. of urea per $100 \mathrm{cc}$. of blood were found while in the group of female subjects the values were respectively $39.0,11.0$ and $24.4 \mathrm{mgm}$. of urea per $100 \mathrm{cc}$. of blood. The mean of the male group is 35 per cent higher than the mean of the female group.

Certain results, although not conclusive, suggest that there is a tendency for the blood urea concentration to increase with age.

\section{BIBLIOGRAPHY}

1. MacKay, E. M., and MacKay, Lois L., J. Clin. Invest., 1927, iv, $127 \cdot$ The Relation of the Blood Urea Concentration to the Amount of Functioning Renal Tissue.

2. Folin, O., and Denis, W., J. Biol. Chem., 1913, xiv, 29. Protein Metabolism from the Standpoint of Blood and Tissue Analysis.

3. McLean, F. C., and Selling, L., J. Biol. Chem., 1914, xix, 31. Urea and Total Non-protein Nitrogen in Normal Human Blood: Relation of Their Concentration to Rate of Elimination.

4. Bang, I., Biochem. Zeitschr., 1915, lxxii, 104. Untersuchungen über den Reststickstoff des Blutes.

5. McLean, F. C., J. Exp. Med., 1915, xxii, 212. The Numerical Laws Governing the Rate of Excretion of Urea and Chlorides in Man.

6. Gettler, A. O., and Baker, W., J. Biol. Chem., 1916, xxv, 211. Chemical and Physical Analysis of Blood in Thirty Normal Cases.

7. Schwartz, H., and McGill, C., Arch. Int. Med., 1916, xvii, 42. Blood Urea Determinations in 211 Cases.

8. Addis, T., and Watanabe, C. K., Arch. Int. Med., 1917, xix, 507. The Causes of Variation in the Concentration of Urea in the Blood of Young Healthy Adults.

9. Folin, O., and Berglund, H., J. Biol. Chem., 1922, li, 395. The Retention 
and Distribution of Amino Acids with Especial Reference to Urea Formation.

10. Klisiecki, A., Biochem. Zeitschr., 1926, clxxvi, 490 . Utber einen regelmässigen Unterschied in der Zusammensetzung des männlichen und weiblichen Menschenblutes.

11. Addis, T., J. Lab. and Clin. Med., 1924, x, 402. Urea Determinations in Blood and Urine.

12. Aub, J. C., and Du Bois, E. F., Arch. Int. Med., 1917, xix, 823. The Basal Metabolism of Old Men. 